\title{
ARTIGOS
}

Submetido em 06.01.2014. Aprovado em 04.06.2014

Avaliado pelo sistema double blind review. Editores Científicos: Delane Botelho, Edgard Barki e Juracy Gomes Parente

DOI: http://dx.doi.org/10.1590/So034-759020140602

\section{RESPONSABILIDADE AMBIENTAL E LEALDADE DE CLIENTES EM BANCO DE VAREJO}

\author{
Environmental responsability and customers loyalty in retail bank \\ Responsabilidad ambiental y lealtad de clientes en banco de comercio minorista
}

\begin{abstract}
RESUMO
Pesquisadores têm sugerido a validade da introdução da gestão ambiental às estratégias de marketing, contudo nenhuma atenção foi dada à predição da lealdade de clientes de instituições financeiras em decorrência dos posicionamentos ambientais de seus bancos. 0 objetivo da pesquisa é mensurar se a percepção de clientes pessoas físicas de que um banco de varejo no Brasil é ambientalmente responsável explica a satisfação, a confiança e as lealdades atitudinal e comportamental. Desenvolveu-se um estudo empírico de natureza descritiva, cujos dados foram coletados por meio de uma survey em uma amostra de 914 correntistas de um banco de varejo no Brasil e analisados pela Modelagem de Equações Estruturais. A percepção do consumidor de que um banco de varejo é ambientalmente responsável explicou a satisfação e a confiança. A satisfação foi mais relevante na estimação da lealdade atitudinal do que a confiança, contudo tanto satisfação quanto confiança não explicaram a lealdade comportamental.
\end{abstract}

PALAVRAS-CHAVE | Banco, responsabilidade ambiental percebida, satisfação, confiança, lealdade.

\begin{abstract}
Researchers have suggested the validity of introduction of environmental management to marketing strategies. However, no attention has been given to the prediction of consumers loyalty to banking organizations as a result of their banks' environmental positioning. The objective of this research is to measure if the perception that a retail bank is environmentally responsible explains the satisfaction, the trust and the attitudinal and behavioral loyalty of costumers. An empirical study of a descriptive nature was developed. Its data was collected by means of a survey sample of 914 checking account holders from a retail bank in Brazil and analyzed by Structural Equation Modelling technique. The customer's perception of an environmentally responsible retail bank can explain satisfaction and trust. On the other hand, satisfaction was more relevant in estimating attitudinal loyalty than trust. However, neither satisfaction nor trust explained behavioral loyalty.
\end{abstract}

KEYWORDS I Bank, perceived environmental responsibility, satisfaction, trust, loyalty.

\section{RESUMEN}

Algunos investigadores han sugerido la validez de la introducción de la gestión ambiental a las estrategias de marketing, sin embargo no se dio ninguna atención a la predicción de la lealtad de clientes de instituciones financieras como consecuencia de los posicionamientos ambientales de sus bancos. El objetivo de la investigación es mensurar si la percepción de clientes personas físicas de que un banco de comerciantes minorista en Brasil es ambientalmente responsable explica la satisfacción, la confianza y las lealtades de actitud y comportamiento. Se desarrolló un estudio empírico de naturaleza descriptiva, cuyos datos fueron recolectados por medio de una survey en una muestra de 914 clientes de un banco de comerciantes minoristas en Brasil y analizados por el Modelaje de Ecuaciones Estructurales. La percepción del consumidor de que un banco de comercio es ambientalmente responsable explicó la satisfacción y la confianza. La satisfacción fue más relevante en la estimación de la lealtad de actitud que la confianza, sin embargo tanto satisfacción como confianza no explicaron la lealtad comportamental.

PALABRAS CLAVE / Banco, responsabilidad ambiental percibida, satisfacción, confianza, lealtad.

PATRICK MICHEL FINAZZI SANTOS

patrickmichel@hotmail.com Administracão, Universidade de Brasília-Brasília-DF, Brasil

rafaelporto@unb.br

Professor do Programa de Pós Graduação em Administração, Universidade de Brasília - Brasília - DF, Brasil 


\section{INTRODUÇÃO}

O despertar da consciência ecológica dos consumidores, a pressão de grupos ativistas, a busca por eficiência operacional e o recrudescimento das legislações ambientais têm impelido os bancos a incluírem a temática ambiental em suas discussões mercadológicas (Paiva, 2010). Ao adotarem e comunicarem práticas ecológicas, os bancos investem em um conjunto de atividades que podem levar os stakeholders a percebê-los como confiáveis, honestos e responsáveis, bem como induzir trocas duradouras com seus clientes (Weber, 2005).

0 desenvolvimento de iniciativas em responsabilidade ambiental sob a égide do marketing pode proporcionar algumas oportunidades aos bancos (Thompson, 1998). Uma delas é a possibilidade de aperfeiçoar sua imagem e reputação, apresentando-se como ecologicamente responsável e, assim, atrair ou manter consumidores que creditam alguma importância a esse comportamento para relacionar-se com um banco. Outro benefício é a diversificação dos negócios, ao atingir nichos específicos de clientes que demandam linhas de crédito para financiamento de empreendimentos ambientais ou fundos de investimentos ecologicamente responsáveis. Por fim, o potencial de redução de despesas concernentes às operações (como água, luz e papel) e que, ao mesmo tempo, permitem diminuir o impacto das atividades no meio ambiente constitui um atrativo adicional para que os bancos incorporem a gestão ambiental às estratégias mercadológicas (Thompson, 1998; Weber, 2005).

Apesar de Grove, Fisk, Pickett e Kangun (1996) indicarem a viabilidade mercadológica da introdução da gestão ecológica às estratégias de marketing no setor de serviços, nenhuma atenção foi dada, na literatura acadêmica, à predição da lealdade de clientes de organizações bancárias em decorrência do posicionamento ambiental dos bancos. Para Oliver (2010), a lealdade é o profundo comprometimento do consumidor pela recompra ou pelo favorecimento a um produto ou marca, apesar do contexto situacional e dos esforços de marketing com potencial de causarem um comportamento de troca. 0 estudo da lealdade nessa indústria é oportuno, pois se espera que clientes leais a um banco (a) utilizem e recomendem os produtos e serviços de uma marca de maneira continuada e (b) proporcionem maior rentabilidade comparativamente aos clientes com baixo nível de lealdade (Lewis \& Soureli, 2006).

Interações reiteradas do consumidor com o banco geram um repertório de avaliações sobre o desempenho da empresa, manifestadas pela satisfação e confiança na marca, que podem influenciar a preferência subsequente pelo prestador, sinalizando a lealdade (Prado, 2004). Por outro lado, a consciência e o conhecimento ambiental, o desempenho de comportamentos pró-meio ambiente e a congruência entre os valores do consumidor e o esforço ambiental da empresa podem favorecer percepções positivas em relação a produtos com atributos ecológicos ou a empresas com ações em responsabilidade ambiental (Chan \& Lau, 2000; Fraj \& Martinez, 2006).

As interações de relacionamento e as percepções positivas sobre a atuação ambiental podem, assim, colaborar na formação da satisfação e da confiança (Han, Hsu, Lee, \& Sheu, 2011), já que estas sumarizam o conjunto de conhecimento e experiências dos consumidores com o banco. Por derradeiro, maiores níveis de satisfação e confiança contribuem para a geração de lealdade (Prado, 2004).

Considerando o debate precedente, este trabalho propõe responder à seguinte pergunta: a percepção de clientes pessoas físicas de que um banco de varejo no Brasil é ambientalmente responsável explica a satisfação, a confiança e a lealdade desses clientes ao banco?

A escolha da indústria financeira como objeto de investigação decorre da constante interação e presença, direta e indireta, dos bancos no dia a dia das pessoas, uma vez que atuam como facilitadores da circulação de recursos entre os agentes econômicos. As instituições financeiras são atores críticos para a sustentabilidade ambiental, pois, ao financiarem as atividades econômicas, estimulam o fluxo de matérias-primas, produtos acabados, empregos e a qualidade do ambiente natural (Paiva, 2010).

0 tema lealdade do consumidor tem sido discutido sob diversos prismas, tanto no Brasil quanto no Exterior. Em um levantamento de artigos em anais dos encontros da ANPAD, periódicos científicos nacionais (Qualis $A_{1}$ a $B_{3}$ em Administração) e internacionais (bases de dados Proquest, Emerald, Gale, Sage, JSTOR, Wilson, Sciente Direct e Wiley) e em teses e dissertações defendidas no Brasil, utilizando os termos "lealdade" e "loyalty", identificaram-se 138 trabalhos, entre 2001 e 2011, que trataram o tema aplicado à indústria financeira. Desses, nenhum abordou a lealdade sob a ótica da gestão ambiental ou da responsabilidade ambiental, enquanto sete artigos associaram o constructo à responsabilidade social.

A despeito do que se tem preconizado sobre os benefícios mercadológicos da implementação de ações ecológicas pelas empresas, não se localizaram estudos empíricos que avaliassem, sob a perspectiva do consumidor, os vínculos entre os esforços em gestão ambiental dos bancos e a lealdade dos clientes. A ausência de um embasamento empírico traz à tona a fragilidade teórica sobre a qual assentam o posicionamento ambiental de grande parte das instituições financeiras 
brasileiras. Logo, o presente estudo pretende discutir o papel desempenhado pelas ações ecológicas dos bancos na construção da lealdade dos seus clientes.

\section{REFERENCIAL TEÓRICO}

Ao desenvolver a perspectiva ecológica do marketing, as empresas esperam gerar e facilitar trocas que satisfaçam as necessidades e os desejos dos consumidores com o mínimo de impacto negativo ao ambiente natural (Gordon, Carrigan, \& Hastings, 2011). Entretanto, para que tal orientação seja exitosa em relação às respostas do consumidor, é necessário avaliar de que maneira seus valores pessoais e comportamentos ambientais interagem com a satisfação.

Os valores representam os critérios que os indivíduos usam para selecionar e justificar suas ações, bem assim valorar objetos e as condutas dos outros (Schwartz, 1992). Dado que são desenvolvidos com base na história de aprendizagem, os indivíduos manifestam seus valores ambientais por meio de comportamentos pró-ecológicos, que podem ser desde o descarte adequado de lixo até a preferência por fornecedores com ações em responsabilidade ambiental (Fraj \& Martinez, 2006). Todavia, Romeiro (2006) encontrou evidências de que a postura ambientalmente correta de um indivíduo se dá sob diversos comportamentos e que determinada ação favorável ao meio ambiente não condiciona a adesão aos demais comportamentos ecologicamente adequados.

Por consequência, ainda que os valores pessoais do consumidor favoreçam a sua predisposição por agir em respeito ao meio ambiente, não se pode assegurar que se manifestará pela preferência por prestadores que desenvolvem ações de responsabilidade ambiental. Isso se deve, sobretudo, ao contexto situacional em que o comportamento ambiental é desempenhado (Corraliza \& Berenguer, 2000) e ao papel de moderação exercido por variáveis associadas ao relacionamento comercial, como é o caso do valor percebido e da satisfação (Schlegelmilch, Bohlen, \& Diamantopoulos, 1996).

Um dos caminhos que o consumidor percorre para desempenhar um comportamento leal é por meio de sua satisfação com a marca. Trata-se do julgamento de que uma característica do produto/serviço, ou o produto/serviço em si, ofereceu (ou está oferecendo) um nível prazeroso de contentamento relativo ao consumo (Oliver, 2010). De acordo com Chen (2010), se uma empresa atua no sentido de atender as necessidades, os desejos e as expectativas ecológicas do consumidor, é possível que este demonstre maior contentamento e consentimento com a empresa e, portanto, maior satisfação.
No processo de formação da satisfação, o consumidor desenvolve uma avaliação sumarizada e global em que compara as expectativas em torno do relacionamento com a percepção de desempenho (Prado, 2004).

Segundo seus valores pessoais, o reconhecimento das práticas ambientais pelo consumidor pode desenvolver um senso de conexão e identificação com a marca, favorecendo uma maior percepção de valor e, por conseguinte, maior satisfação (Luo \& Bhattacharya, 2006). Ao se certificar que as necessidades, desejos e expectativas em relação ao meio ambiente podem ser preenchidos pelo esforço ambiental de uma instituição financeira, espera-se que o cliente avalie positivamente o relacionamento, manifestando maior satisfação. Por isso, conjectura-se:

H1: quanto maior a percepção de um cliente pessoa física de que um banco é ambientalmente responsável, maior a sua satisfação com ele.

Além da satisfação, a confiança é outro caminho percorrido pelo consumidor em direção à lealdade a uma marca. Trata-se de uma variável intrínseca aos relacionamentos duradouros, pois provém de reiterados contatos ao longo do tempo entre os parceiros (Brei \& Rossi, 2005). A repetição dos ciclos de trocas, os riscos assumidos e o cumprimento das expectativas fortalecem a disposição das partes em confiar uma na outra, assim como aumentam o fluxo de troca dos recursos envolvidos no relacionamento (Baumann, Elliott, \& Hamin, 2011). A confiança do consumidor manifesta-se pela expectativa de que a empresa se comportará de maneira competente, altruísta e honesta no relacionamento (Sirdeshmukh, Singh, \& Sabol, 2002; Sweeney \& Swait, 2008).

Algumas empresas têm lançado produtos que não entregam os atributos ambientais prometidos ou sobrevalorizam-nos em suas ações comunicacionais. De igual modo, por vezes, a postura socioambiental da empresa é incoerente com os atributos ambientais comunicados em seus produtos, o que tem desencadeado reações de desconfiança e de ceticismo por parte dos consumidores diante de apelos ecológicos das empresas (Romeiro, 2006). Segundo Weber (2005), os bancos adotam e divulgam suas iniciativas ambientais com a finalidade de serem percebidos como confiáveis e responsáveis.

A confiança ao banco pode ser favorecida pela crença de que ele cumpre suas promessas, inclusive as que dizem respeito à atuação ecológica. Ao perceber o comprometimento do banco em prol do meio ambiente, presume-se que o consumidor reconheça comportamentos altruístas e íntegros por parte do banco. Dessa maneira, pode enxergar menores riscos na relação, colaborando com o aumento da confiança. Emerge, pois: 
H2: quanto maior a percepção de um cliente pessoa física de que um banco é ambientalmente responsável, maior a sua confiança no banco.

A confiança desenvolve-se com base em contatos diretos (por exemplo, procura, aquisição, consumo e descarte) e indiretos (por exemplo, propaganda, boca a boca e imagem) com a marca. Como uma avaliação global de contentamento com a experiência de consumo, a satisfação cumulativa indica que a marca tem atendido de maneira estável suas promessas no que tange à entrega de benefícios utilitários e simbólicos (Delgado-Ballester \& Munuera-Aleman, 2001), favorecendo a percepção de credibilidade da marca pelo consumidor (Oliver, 2010).

Prado (2004) e Brei e Rossi (2005) defendem que a satisfação, por si só, não é suficiente para gerar a lealdade, dado que é mediada pela confiança. Os estudos de Prado (2004) e Kantsperger e Kunz (2010) confirmaram que a satisfação é um preditor positivo e significante da confiança em uma organização bancária. Decorre, portanto:

H3: quanto maior a satisfação de um cliente com um banco, maior a sua confiança nele.

Não há um consenso quanto à definição e operacionalização da lealdade, contudo grande parte das pesquisas tem sido pautada por duas abordagens. Na abordagem comportamental, a lealdade é expressa por meio dos comportamentos passados de compras do consumidor. 0 objeto de estudo são os padrões de compras reiteradas de um consumidor de determinado produto ou a proporção em que esse padrão ocorre, ao longo do tempo, diante de um conjunto de alternativas disponíveis (Uncles, Dowling, \& Hammond, 2003). Essa lente tem recebido ponderações, por não levar em conta as motivações internas e o comprometimento do consumidor com a marca (Baumann et al., 2011).

Ampliando as discussões sobre o tema, a segunda abordagem, a atitudinal, considera a favorabilidade do consumidor expressa por meio do seu comprometimento, preferência, sentimentos e crenças positivas em favor da marca, predisposição em recomendá-la para terceiros (boca a boca) e intenções em permanecer comprando-a, apesar de ofertas de marcas concorrentes (Jones \& Taylor, 2007). Apesar de sua proposta integradora, críticas recaem sobre a abordagem. Alguns de seus adeptos não contemplam o comportamento revelado do consumidor, limitando-se às variáveis da dimensão atitudinal (Uncles et al., 2003).

Gremler e Brown (1996), ao compararem a lealdade no setor de serviços com a lealdade nos setor de manufaturados, sugeriram que: (a) a lealdade é maior ou mais prevalente nos consumidores de serviços do que nos de bens físicos; (b) a inseparabilidade de provedor e consumidor no processo de produção e entrega do serviço pode proporcionar uma maior interação interpessoal, o que, por seu turno, geralmente leva a uma maior lealdade; (c) o risco percebido normalmente é maior na aquisição de serviços do que na compra de produtos físicos, fazendo com que a lealdade atue como um mecanismo de minimização de riscos; e (d) em alguns serviços, notadamente os de vínculos contratuais (por exemplo, serviços bancários, serviços telefônicos e planos de saúde), há mais barreiras à mudança de fornecedor do que na troca de marcas de produtos tangíveis.

Consumidores satisfeitos são mais propensos a manterem interações de longo prazo com uma marca, a realizarem boca a boca positivo e a resistirem a ofertas de concorrentes (Chiou \& Droge, 2006; Oliver, 2010). Assim, a satisfação tem sido considerada como um relevante preditor da lealdade dos consumidores (Oliver, 2010). Na indústria financeira, tanto no Brasil quanto no Exterior, estudos têm apontado para uma associação positiva entre satisfação e lealdade (Prado, 2004; Licata \& Chakraborty, 2009). Portanto, propõe-se:

H4: quanto maior a satisfação de um cliente com um banco, maior a sua lealdade atitudinal ao banco.

$\mathrm{H}_{5}$ : quanto maior a satisfação de um cliente com um banco, maior a sua lealdade comportamental ao banco.

Brei e Rossi (2005) arguem que a confiança em um prestador de serviços é essencial à formação da lealdade. Isso decorre, principalmente, pelo fato de que as ações do provedor no sentido de desenvolver a confiança podem reduzir o risco percebido pelo consumidor, permitindo-lhe elaborar predições acerca do comportamento futuro do prestador em direção à continuidade do relacionamento (Kantsperger \& Kunz, 2010). As pesquisas de Prado (2004) e Brei e Rossi (2005) sustentam as evidências de que a confiança é um antecedente da lealdade dos clientes aos bancos.

H6: quanto maior a confiança de um cliente em um banco, maior a sua lealdade atitudinal ao banco.

H7: quanto maior a confiança de um cliente em um banco, maior a sua lealdade comportamental ao banco.

Derivada das hipóteses de pesquisa, a Figura 1 retrata 0 modelo conceitual submetido ao exame empírico. Por questão de parcimônia, o constructo percepção de que um banco é ambientalmente responsável será identificado como gestão ambiental nas figuras e tabelas que contenham suas informações ou resultados. 
Figura 1. Modelo conceitual

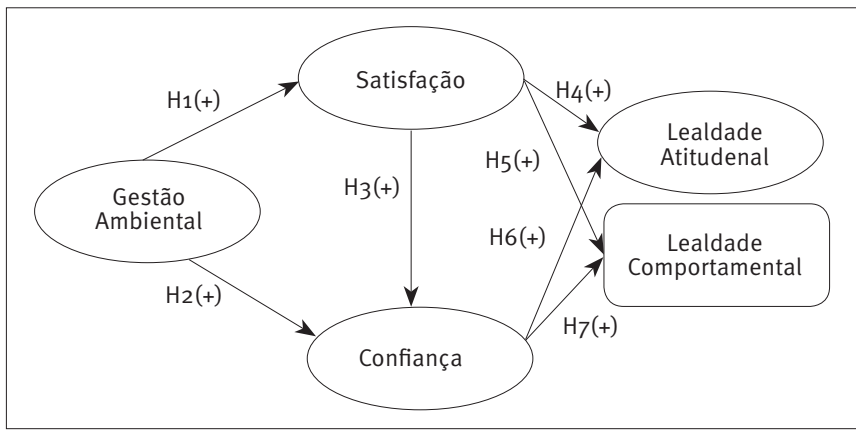

Legenda: H - Hipótese; (+) Associação positiva entre as variáveis.

Nota: As elipses representam variáveis latentes e o retângulo, variável observável.

\section{PROCEDIMENTOS METODOLÓGICOS}

Para responder à pergunta de pesquisa, realizou-se uma pesquisa descritiva (correlacional) por meio de uma survey com corte transversal entre sujeitos. A população do estudo é formada por clientes pessoas físicas detentores de conta-corrente no Brasil em um relevante banco de varejo, cuja identidade não pode ser revelada, mas será designado Banco X. O banco posiciona-se entre os cinco maiores bancos em operações no Brasil em ativos (ano-base 2011).

A unidade amostral é o cliente pessoa física, primeiro titular de conta-corrente no Banco X, com pelo menos um ano de relacionamento, sem restrições cadastrais (por exemplo, Serasa, SPC, CCF) anotadas por instituições financeiras e formação educacional igual ou superior ao primeiro grau. Empregou-se a amostragem aleatória simples (seleção aleatória dos respondentes em um banco de dados do Banco X com 30 mil correntistas), sem reposição e com abrangência nacional.

Optou-se por um instrumento de coleta de dados estruturado, aplicado por um instituto de pesquisa por meio de entrevistas telefônicas assistidas por computador. Previamente ao início do campo, procedeu-se a um pré-teste do questionário com 30 clientes. Após os ajustes do pré-teste, entrevistaram-se 914 sujeitos nos meses de agosto e setembro de 2011.

Uma vez que não se localizou qualquer escala de avaliação da percepção ou do reconhecimento por parte de consumidores das ações de gestão ambiental na indústria financeira, optou-se por desenvolvê-la. Para tal, adotaram-se sugestões de Churchill (1979) e Pasquali (2010), ressalvando que, por restrições orçamentárias, não foi possível replicar a escala em uma amostra independente.

Para a validação teórica da escala, inicialmente, levantaram-se, na literatura acadêmica, 21 iniciativas de gestão ambiental aplicáveis a bancos. Após a realização de seis entrevistas em profundidade com clientes e gestores, a crítica da área de desenvolvimento sustentável do banco e a avaliação de quatro juízes (doutores pesquisadores em gestão ambiental), as iniciativas foram purificadas, redundando em oito itens que compuseram a escala de avaliação da percepção de que um banco é ambientalmente responsável. Na pesquisa, o constructo foi definido como a percepção, por parte do consumidor, de que o banco empenha-se em atuar respeitosamente em relação ao ambiente natural, por intermédio de um conjunto de iniciativas que visam beneficiar direta ou indiretamente o meio ambiente.

A satisfação foi avaliada sob a perspectiva acumulativa (12 meses anteriores à entrevista) por meio de três itens adaptados de Fornell, Johnson, Anderson, Cha e Bryant (1996), em uma escala de cinco pontos (satisfação geral - de muito insatisfeito a muito satisfeito; desconformidade global - de muito abaixo das expectativas a muito acima das expectativas; distância da empresa ideal - de muito longe do ideal a muito próximo do ideal). A confiança foi operacionalizada por meio de 11 itens extraídos de Prado (2004), em uma escala tipo Likert com cinco pontos (de discordo totalmente a concordo totalmente). Tanto em confiança quanto em satisfação, adotaram-se as definições constitutivas propostas por Prado (2004).

Por sua vez, a avaliação da lealdade deu-se sob os aspectos atitudinal e comportamental. A lealdade atitudinal foi conceituada, nos termos definidos por Bennett e Rundle-Thiele (2002), como a predisposição favorável do consumidor em direção a um banco, em decorrência de processos psicológicos, manifestada pela preferência e pelo comprometimento com o banco. Assim, as intenções comportamentais em direção ao Banco $X$ serviram de indicadores para mensurar a lealdade atitudinal.

Para operacionalizar a variável, adaptaram-se quatro itens de Matos, Henrique e Rosa (2009) e, de modo complementar, dois itens de Prado (2004). Os itens foram avaliados em uma escala de cinco pontos em que se averiguaram as chances de cada intenção comportamental se concretizar (de muito baixa a muito alta). Dois principais ajustes foram necessários no item que trata das intenções de aumentar os negócios com o banco, retirado de Matos, Henrique e Rosa (2009). Primeiramente, foi desmembrado em cinco itens, de modo a refletir com maior precisão as intenções de negócios do cliente, segundo as principais categorias de produtos financeiros. 0 segundo ajuste foi a estimação do horizonte temporal da expectativa em que cada intenção de negócio se concretizaria, isto é, seis meses (curto prazo).

A dimensão comportamental da lealdade foi mensurada por meio de uma variável observável resultante do produto de dois indicadores: a longevidade do relacionamento e o nível de bancarização (NB), posteriormente transformado. 0 primeiro refere-se ao tempo, em anos, há que o cliente relaciona-se com o banco 
como correntista e foi acessado nas bases de dados do Banco X. O segundo indicador revela a quantidade de bancos com que o cliente se relaciona e foi obtido mediante uma pergunta no instrumento de coleta de dados. Previamente à composição da variável, procedeu-se à transformação do nível de bancarização (NBt):

$\mathrm{NBt}=6-\mathrm{NB}$

Em que: (a) 6 é a soma de 1 com o maior nível de bancarização identificado na amostra (cinco bancos) e (b) NB é o nível de bancarização (como todos são correntistas do Banco X, o menor valor possível é 1). O valor mínimo de NBt é 1 (situação em que o cliente relaciona-se com cinco bancos) e o máximo é 5 (quando o cliente relaciona-se apenas com o Banco X).

A longevidade do relacionamento foi multiplicada pelo nível de bancarização transformado. Uma das manifestações da lealdade verdadeira é a manutenção de um relacionamento monogâmico com um banco. Com a transformação da variável nível de bancarização, quanto mais tempo um respondente mantém conta-corrente no Banco $X$ e quanto menos esse relacionamento é compartilhado com outros bancos, maior é a lealdade comportamental do sujeito ao banco. Em outras palavras, indica um relacionamento duradouro e exclusivo com o banco ou pouco compartilhado com outros bancos. Quanto menor for esse produto, menos leal é o cliente, uma vez que o relacionamento pode ser mais recente e compartilhado com outros bancos.

Antes das análises, conduziu-se o exame exploratório dos dados conforme Hair, Anderson, Tatham e Black (2005). Identificaram-se 36 sujeitos com ao menos um dado faltante em itens dos constructos. Localizaram-se 85 outliers multivariados por meio da medida $D^{2}$ de Mahalanobis ( $\left.p<0,001\right)$. Optou-se por mantê-los por representarem um subgrupo relevante na amostra. Observou-se que as variáveis não seguiam uma distribuição normal univariada, não possuíam padrões de não linearidade e não apresentaram indícios de multicolinearidade. Findo o exame exploratório, decidiu-se excluir os sujeitos com ao menos um dado faltante, redundando em uma amostra final de 878 respondentes.

\section{RESULTADOS DESCRITIVOS E VALIDAÇÃO EMPÍRICA DOS CONSTRUCTOS}

A média de idade dos respondentes é de 53 anos e $56 \%$ são do sexo feminino. A maior parte dos entrevistados possui o nível superior completo de formação (72,5\%), 60,3\% são empregados (privado ou público), 32,6\% são aposentados/pensionistas e somente 3,5 \% são autônomos. 43,3\% da amostra declarou possuir renda média mensal superior a $\mathrm{R} \$ 6.000,00$, enquanto $6,9 \%$ in- formaram renda igual ou inferior $\mathrm{R} \$ 1.000,00$. No relacionamento bancário, $90 \%$ afirmaram que recebem no Banco $X$ a renda decorrente das atividades profissionais e $50,7 \%$ relacionam-se exclusivamente com o Banco X (média = 1,6 banco). A média do tempo de relacionamento com o Banco Xé de 15,4 anos.

A Tabela 1 sintetiza os resultados descritivos dos itens dos constructos percepção de que um banco é ambientalmente responsável (de GA1 a GA8), satisfação (de SAT1 a SAT3), confiança (de CON1 a CON11) e lealdade atitudinal (de LA 1 a LA10). No que se refere à variável lealdade comportamental, tem-se: valor mínimo igual a 3, valor máximo igual a 290, média de 68,17 e desvio-padrão de 44,32. Quatro sujeitos representativos do valor mínimo eram clientes de três bancos e relacionavam-se com o Banco X há um ano. Por seu turno, o valor máximo proveio de um respondente que era exclusivamente cliente do Banco $X$ em um relacionamento de 58 anos.

A validação empírica das escalas dos constructos deu-se pela Análise Fatorial Exploratória (AFE), Análise Fatorial Confirmatória (AFC) e pela avaliação das validades convergente e discriminante. Cada constructo foi submetido a uma AFE com o uso do programa SPSS. Previamente à estimação inicial dos fatores, confirmou-se a fatorabilidade da matriz de correlação dos dados (matriz R).

As extrações das variáveis latentes fundamentaram-se no método da análise dos componentes principais, com a rotação varimax (ortogonal), quando fosse o caso. Foi extraído um componente (fator) nos constructos percepção de que um banco é ambientalmente responsável, satisfação e confiança, ao passo que, em lealdade atitudinal, extraíram-se dois componentes. Em relação à percepção de que um banco é ambientalmente responsável, os resultados das cargas fatoriais $(0,80 \sim 0,86)$, comunalidades $(0,63 \sim 0,75)$, variância explicada $(69,2 \%)$ e alfa de Cronbach $(0,94)$ apresentaram-se pertinentes. Situações semelhantes de adequação ocorreram com satisfação e confiança.

Especificamente quanto à lealdade atitudinal, observou-se que LA1 a LA5 e LA6 a LA10 carregaram em dois componentes distintos, respectivamente, componente 1 e componente 2 . No primeiro componente as cargas variaram de 0,66 a 0,80, enquanto as comunalidades dos itens oscilaram entre 0,47 e 0,74. As cargas dos cinco itens do componente 2 oscilaram entre 0,64 e 0,79, enquanto as comunalidades variaram de 0,47 a 0,64. A variância explicada pela solução fatorial foi de $58,2 \%$. No teste do alfa de Cronbach, o primeiro componente obteve 0,79 , contudo a exclusão de LA5 aumentaria o indicador para 0,82. Ao examinar detalhadamente o item, observou-se que o seu traço comportamental já estava sob avaliação em LA2. Optou-se por excluí-lo, de modo que o componente 1 passou a ser composto pelos itens LA1 a LA4. O alfa de Cronbach do segundo componente foi de 0,80 , considerado adequado para esta pesquisa. 


\section{TABELA 1. Resultados descritivos dos itens dos constructos}

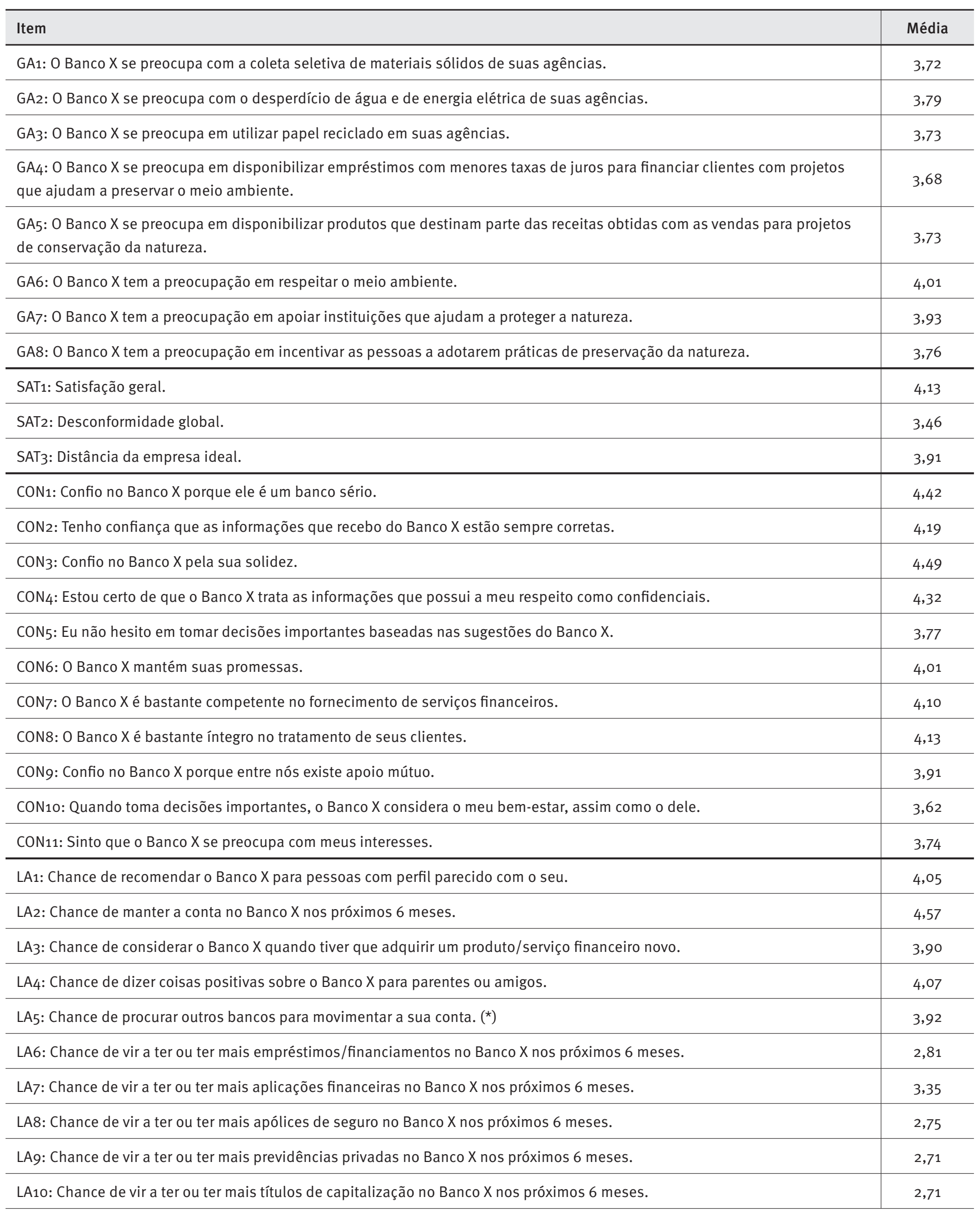

Legenda: $\left(^{\star}\right)$ Item com a escala transformada no processo de validação empírica. 
Com a definição dos itens, passou-se à designação dos componentes. 0 primeiro componente, nomeado como intenções de recomendação e de permanência, abarca itens atinentes às intenções de recomendação (LA1 e LA4), de permanência (LA2) e de preferência ao banco (LA3). O segundo componente (LA6 a LA10) abrange as intenções comportamentais associadas à aquisição de categorias de produtos financeiros e foi designado como intenções de negócios.

Em seguida, realizou-se a AFC dos constructos com a finalidade de confirmar se o conjunto de variáveis observáveis (itens) representava adequadamente os constructos em avaliação (Kline, 2011). A AFC, a avaliação do modelo de mensuração e a estimação do modelo estrutural deram-se por meio da Modelagem de Equações Estruturais (MEE), operacionalizada com o programa EQS 6.1. Optou-se pela matriz de variância-covariância para entrada dos dados nos modelos e pelo método de estimação Elliptical Reweighted Least Squares (ERLS), dado que grande parte das variáveis não possui distribuição normal. 0 método não exige normalidade multivariada (Kline, 2011). Nos quatro constructos, obtiveram-se resultados satisfatórios nos

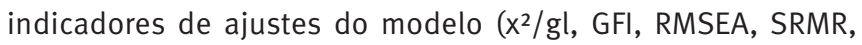
$\mathrm{NFI}, \mathrm{TLI}, \mathrm{CFI}$ e IFI), nos coeficientes não padronizados e padronizados, na confiabilidade composta e na variância extraída, nos termos indicados por Tabachnick e Fidell (2007).

Com base nas Análises Fatoriais Confirmatórias, avaliou-se o modelo de mensuração geral pela estimação das covariân- cias entre os constructos em conjunto (Kline, 2011). Os resultados apresentaram-se adequados, segundo proposto por Kline (2011). Obteve-se, também, a validade discriminante dos constructos por meio de suas correlações e do método oferecido por Bagozzi e Philips (1982). Dessa maneira, atestaram-se a consistência interna dos indicadores representativos dos constructos, a relevância dos itens na representação comportamental dos traços latentes, a validade convergente dos constructos e a discriminação entre estes no que tange aos fenômenos que medem.

\section{AVALIAÇÃO DO MODELO ESTRUTURAL E TESTES DE HIPÓTESES}

Verificou-se a adequação da matriz de variância-covariância da amostra com a matriz hipotetizada pelas relações do modelo, conforme limites expressos entre parênteses indicados por Tabachnick e Fidell (2007): $\mathrm{x}^{2} / \mathrm{gl}(\leq 5)=2,6$; GFI $(\geq 0,90)=0,90$; $\operatorname{RMSEA}(\leq 0,05)=0,04 ; \operatorname{SRMR}(\leq 0,05)=0,04 ; \mathrm{NFI}(\geq 0,90)=0,98$; $\operatorname{TLI}(\geq 0,90)=0,99$; $\operatorname{CFI}(\geq 0,90)=0,99 ;$ IFI $(\geq 0,90)=0,99$. Os testes das hipóteses de pesquisa deram-se pelas magnitudes e níveis de significância dos coeficientes de regressão das relações presumidas entre os constructos e a lealdade comportamental, conforme a Tabela 2.

\section{TABELA 2. Testes das hipóteses de pesquisa}

\begin{tabular}{|c|c|c|c|c|}
\hline Relação Estrutural & b & $\beta$ & Hipótese & Status $(*)$ \\
\hline Gestão Ambiental ...... Satisfação & $0,49\left(^{*}\right)$ & 0,55 & $\mathrm{H}_{1}$ & Aceita \\
\hline Gestão Ambiental … & $0,14(*)$ & 0,19 & $\mathrm{H} 2$ & Aceita \\
\hline Satisfação …… Confiança & $0,61\left(^{\star}\right)$ & 0,77 & $\mathrm{H}_{3}$ & Aceita \\
\hline Satisfação ….. Lealdade Atitudinal & $0,97(*)$ & 0,86 & $\mathrm{H}_{4}$ & Aceita \\
\hline Satisfação ….. Lealdade Comportamental & 2,74 & 0,04 & $\mathrm{H}_{5}$ & Rejeitada \\
\hline Confiança ..... & 0,07 & 0,05 & H6 & Rejeitada \\
\hline Confiança ...... Lealdade Comportamental & 5,97 & 0,08 & $\mathrm{H}_{7}$ & Rejeitada \\
\hline
\end{tabular}

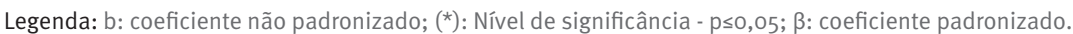

Confirmou-se a Hipótese 1 de que quanto maior a percepção de um cliente pessoa física de que um banco é ambientalmente responsável, maior a sua satisfação com ele. A literatura tem advogado que as práticas em gestão ambiental dos bancos podem favorecê-los no estabelecimento de vínculos de negócios com seus clientes. Tal movimento pode dar-se tanto pela oferta de produtos financeiros com atributos ambientais funcionais e simbólicos quanto pela identificação de valores ecológicos congruentes entre ambos.
Segundo Coyne (1986), consumidores raramente baseiam suas escolhas em características ou práticas de empresas que não sejam refletidas em uma diferença percebida nos produtos ou serviços. Quer dizer, as iniciativas em gestão ambiental de um banco podem implicar algum efeito de natureza subjetiva (por exemplo, satisfação, confiança e lealdade atitudinal) no consumidor, se esse, preliminarmente, reconhecê-las como relevantes para o seu relacionamento com o banco. Os esforços do Banco X no sentido de atender às expectativas ecoló- 
gicas do consumidor, ainda que imbuídas de interesses utilitários ou simbólicos, estão positivamente associados a um maior contentamento e consentimento com o relacionamento e, por consequência, a uma maior satisfação.

A segunda hipótese também foi aceita, ou seja, quanto maior a percepção de um cliente pessoa física de que um banco é ambientalmente responsável, maior a sua confiança nele. No entanto, a magnitude da relação foi menor $(\beta=0,19)$ do que 0 encontrado na primeira hipótese $(\beta=0,55)$. Conforme debatido por Weber (2005), o engajamento ambiental dos bancos também tem como propósito aperfeiçoar a imagem institucional ao disseminar a ideia de que são confiáveis, honestos e responsáveis. Os resultados da pesquisa apontam para uma relação positiva entre a percepção do correntista de que o Banco X é ambientalmente responsável e a confiança no banco.

Tal como sugerido na construção da segunda hipótese, a confiança de um consumidor pode ser favorecida pela crença de que a organização bancária cumpre suas promessas (Sirdeshmukh et al., 2002), inclusive as relacionadas à sua gestão ambiental. Ao perceber o comprometimento do banco em prol do meio ambiente, acredita-se que o consumidor reconheça comportamentos altruístas e íntegros por parte da organização bancária. Dessa maneira, o consumidor pode enxergar menores riscos na relação, favorecendo o aumento da confiança.

A satisfação e a confiança são alguns dos constructos que orientam o processo de decisão do consumidor em relação a uma empresa (Brei \& Rossi, 2005). Segundo as evidências desta pesquisa, ambas as variáveis podem ser explicadas pela percepção de que um banco é ambientalmente responsável, apesar de as intensidades serem distintas. Ainda que sob a esfera das ações de responsabilidade social, Matute-Vallejo, Bravo e Pina (2011) verificaram que o comprometimento e a satisfação dos clientes com um banco são explicados pela percepção que possuem sobre a atuação em responsabilidade social de seus bancos de relacionamento. Dessa maneira, o empenho ecológico apoia a consolidação de avaliações positivas sobre o relacionamento com a instituição financeira.

A Tabela 3 apresenta os coeficientes padronizados $(\beta)$ das relações indiretas entre a percepção de que um banco é ambientalmente responsável, a lealdade atitudinal, as duas dimensões da lealdade atitudinal (intenções de recomendação e de permanência e intenções de negócios) e a lealdade comportamental. Apesar de não se esperarem vínculos diretos entre a percepção de que um banco é ambientalmente responsável e a lealdade atitudinal, ao levar em conta os relacionamentos indiretos, aquela variável passa a ser proeminente na predição da lealdade atitudinal $(\beta=0,50)$, notadamente por meio da satisfação.

\section{TABELA 3. Relações indireta ( $\beta$ ) entre os constructos percepção de que um banco é ambientalmente responsável e lealdade}

\begin{tabular}{|c|c|}
\hline Relação Estrutural & Relação Indireta \\
\hline Gestão Ambiental .... Lealdade Atitudinal & 0,50 \\
\hline $\begin{array}{l}\text { Gestão Ambiental ...: Intenções de } \\
\text { Recomendação e de Permanência }\end{array}$ & 0,48 \\
\hline Gestão Ambiental .... Intenções de Negócios & 0,28 \\
\hline $\begin{array}{l}\text { Gestão Ambiental .... } 3 \text { Lealdade } \\
\text { Comportamental }\end{array}$ & 0,07 \\
\hline
\end{tabular}

Isso implica afirmar que, se algum banco opta por utilizar o seu posicionamento ambiental para forjar predisposições positivas dos clientes em sua direção, é condição indispensável a prestação de serviços de maneira a satisfazer as expectativas dos consumidores, sob o risco de causar alguma reação de ceticismo por parte destes. Episódios de organizações que não cumpriram o prometido no que diz respeito às práticas ambientais e à qualidade de seus produtos e serviços acentuam a incredulidade do consumidor diante dos apelos ecológicos empresariais, tais como as ações de comunicação e os atributos ambientais de produtos (Romeiro, 2006). Ou seja, as ações de gestão ambiental, sob a ótica dos indivíduos, só fazem sentido se a empresa oferece produtos e serviços adequados às expectativas dos clientes, quaisquer que sejam elas.

Quando a lealdade atitudinal é desmembrada nas suas duas dimensões, verifica-se que a percepção de que um banco é ambientalmente responsável explica, em maior magnitude, as intenções de recomendação e de permanência $(\beta=0,48)$ do que as intenções de negócios $(\beta=0,28)$. Mandhachitara e Poolthong (2011) verificaram que o desempenho em responsabilidade social de bancos tailandeses explicava as intenções de recomendação e de preferência dos consumidores, mas não predizia as intenções de negócios com os bancos. Depreende-se que o esforço ambiental de um banco está mais propenso a corroborar o boca a boca positivo do que a propensão à realização de negócios com o cliente.

A percepção de que um banco é ambientalmente responsável é, no entanto, irrelevante para a lealdade comportamental $(\beta=0,07)$, o que coloca em dúvida a efetividade da aplicação meramente comercial da gestão ambiental na indústria bancária. A percepção da atuação ecologicamente responsável de um banco está mais associada, ainda que indiretamente, às intenções de boca a boca positivo e de manutenção do relacionamento do que às predisposições de adquirir mais produtos. Po- 
rém, quando se observa o comportamento em si do correntista, no que diz respeito à lealdade, o vínculo é inexistente.

Por ora, não se pode esperar que a percepção da postura ambiental venha a encorajar intenções comportamentais em favor de um banco ou representar o principal critério de decisão para início, aumento ou encerramento de um relacionamento bancário. Há aspectos contingenciais (como a opção do empregador quanto ao banco de depósito do salário do consumidor) e mercadológicos (vinculados ao composto de marketing) que concorrem para subsidiar aquelas decisões.

A hipótese de que quanto maior a satisfação de um cliente com um banco, maior a sua confiança no banco $\left(\mathrm{H}_{3}\right)$ foi corroborada. Como uma avaliação global de contentamento com a experiência de consumo, a satisfação sinaliza que o Banco $X$ tem cumprido de maneira estável suas promessas no que tange à oferta dos benefícios desejados pelo consumidor, ou seja, a satisfação acumulativa colabora na explicação da percepção de credibilidade do banco pelo consumidor.

A Hipótese 4, de que quanto maior a satisfação de um cliente com um banco, maior a sua lealdade atitudinal ao banco, foi suportada, ao contrário da Hipótese 5 (quanto maior a satisfação de um cliente com um banco, maior a sua lealdade comportamental ao banco), que foi rejeitada pelos dados amostrais. Constata-se que os clientes mais satisfeitos possuem maiores predisposições a realizarem boca a boca positivo, a manterem o relacionamento e aumentarem os negócios com um banco. No entanto, a mesma associação não foi observada quando se trata da faceta comportamental da lealdade.

A satisfação do consumidor não pode ser negligenciada no contexto de trocas relacionais, notadamente nos serviços financeiros, uma vez que atua como preditora da lealdade atitudinal e da confiança dos consumidores. Todavia, nessa indústria, os achados sugerem que clientes satisfeitos não proporcionam, necessariamente, maiores interações comerciais.

Possivelmente isso se deve à concorrência de variáveis contingenciais na explicação da lealdade comportamental (Uncles et al., 2003), tais como o recebimento dos proventos no banco (conta-salário), a renda disponível para aquisição dos produtos do prestador e as próprias necessidades bancárias do cliente. Além disso, as barreiras de saída e a percepção dos custos de mudança de provedor são consideradas altas nesse setor, interferindo nos níveis de lealdade (Matos et al., 2009).

Ao contrário do que foi encontrado em pesquisas que tratam da confiança em contextos relacionais de negócios (Brei \& Rossi, 2005; Prado, 2004), os resultados não sustentam as relações confiança - lealdade atitudinal e confiança - lealdade comportamental. Quer dizer, ao nível de significância de 5\%, rejeitaram-se as Hipóteses 6 e 7. Por outro lado, esses achados encontram suporte teórico nas pesquisas de Moorman, Zaltman e Desphandé (1992) e Grayson e Ambler (1999), cujas evidências apontam para relações diretas fracas ou não significantes entre constructos de orientação relacional, como é o caso da confiança e consumo de serviços de relacionamento de longo prazo, tal como o setor bancário.

Verificou-se que as médias dos itens da confiança (com exceção de CON9) são estatisticamente iguais ( $p>0,05$ ) entre os entrevistados que se relacionam apenas com o Banco X e aqueles que são clientes de pelo menos dois bancos além do Banco X (três bancos de relacionamento). Tantos os clientes monogâmicos quanto os poligâmicos atribuem os mesmos níveis de confiança ao Banco X. Assim, a credibilidade do banco não seria um atributo discriminante na fidelidade de seus clientes, já que se trata de uma característica compartilhada por outros grandes bancos do Sistema Financeiro Nacional.

Ainda que o modelo hipotetizado tenha se ajustado adequadamente à estrutura dos dados amostrais, desenvolveu-se um modelo concorrente para verificar se há relações que representem de maneira mais acurada os fenômenos em estudo. A partir do modelo inicial desta pesquisa, acrescentaram-se relações diretas da percepção de que um banco é ambientalmente responsável para as lealdades atitudinal e comportamental. Todos os indicadores de qualidade de ajustes do modelo inicial e o concorrente apresentaram-se semelhantes. Entretanto, o constructo associado à responsabilidade ambiental não explicou a lealdade atitudinal nem a lealdade comportamental. Esse resultado ratifica a viabilidade teórica do modelo inicial, além de reforçar os achados de que ações de marketing ambiental dos bancos de varejo no Brasil possuem somente efeitos indiretos sobre variáveis de cunho negociais, como a lealdade.

\section{CONCLUSÕES}

A finalidade do artigo foi colaborar com a compreensão da forma como as práticas de gestão ambiental das empresas favorecem o relacionamento com os clientes. Nesse sentido, as implicações teóricas e gerenciais dos achados do estudo podem ser sumarizadas sob três perspectivas.

Em primeiro lugar, a percepção do consumidor de que um banco é ambientalmente responsável explica a satisfação e a confiança ao banco. Esses vínculos positivos evidenciam a viabilidade das práticas de gestão ambiental para apoiar o desenvolvimento de julgamentos e avaliações positivas pelo consumidor sobre um banco. A magnitude da relação indireta com a lealdade atitudinal sustenta a importância da gestão ambiental na formação de intenções comportamentais propícias à 
organização bancária, desde que o consumidor sinta-se satisfeito com os serviços prestados. Por outro lado, notou-se pouca efetividade da gestão ambiental em favorecer a perspectiva comportamental do relacionamento com o cliente.

No momento atual, nota-se que o consumidor brasileiro valoriza, em um fornecedor, primordialmente, o desempenho do composto mercadológico e, acessoriamente, o desempenho ambiental. As proposições teóricas de McDonald e Rundle-Thiele (2008) sugerem que clientes de bancos preferem iniciativas (ecológicas ou não) que lhes proporcionam benefícios diretos às iniciativas socioambientais que abrangem uma amplitude maior de beneficiários. De qualquer maneira, ao optarem por fazer conhecer suas práticas em gestão ambiental, é imprescindivel que os bancos demonstrem aos consumidores de que forma suas ações colaboram na solução de problemas ecológicos ou na preservação do meio ambiente, sob pena de serem percebidas como uma estratégia oportunista de negócios.

Além disso, se desejarem obter algum efeito positivo no comportamento do consumidor em favor à adesão da iniciativa ou da causa ambiental apoiada pelo banco, um caminho seria a combinação de um conjunto de ações: (a) especificar de maneira clara os benefícios ao consumidor e ao meio ambiente do engajamento à iniciativa ou à causa ambiental; (b) dar feedbacks regulares aos partícipes quanto aos resultados alcançados na execução da iniciativa ambiental, demonstrando a efetividade do comportamento desempenhado pelo consumidor; e (c) oferecer ao consumidor recompensas, financeiras ou não, pelo engajamento à iniciativa ambiental (Cone \& Hayes, 1977).

Em segundo lugar, a não confirmação dos vínculos satisfação - lealdade comportamental e confiança - lealdade comportamental revela a importância de se evidenciar a forma como constructo lealdade é avaliado. Grande parte dos trabalhos sobre lealdade referenciados nesta pesquisa, na verdade, trata da dimensão atitudinal, todavia poucos diferenciam, em seus achados, a lealdade atitudinal da lealdade comportamental. Por vezes, generalizações são feitas a respeito do efeito de variáveis preditoras na lealdade, sem distinguir quais dimensões estão sendo explicadas. Como observado, magnitudes distintas foram verificadas nas relações entre satisfação e confiança e as dimensões da lealdade. Tomadas em conjunto as pesquisas selecionadas no referencial teórico, nota-se que a satisfação e a confiança são relevantes na explicação da lealdade atitudinal, contudo o mesmo não se pode asseverar sobre a lealdade comportamental.

Em terceiro lugar, ao contrário do que foi verificado por Sirdeshmukh et al. (2002) e Brei e Rossi (2005), é possível, em um contexto de trocas relacionais, que a confiança não seja o principal determinante da lealdade atitudinal a uma empresa de serviços. Essa situação pode acontecer quando os principais concorrentes da prestadora também são percebidos como críveis e, portanto, não se trataria de um atributo discriminante das intenções comportamentais do consumidor. Isso não implica afirmar que a confiança é desnecessária na explicação da lealdade a um banco, pelo contrário, o negócio bancário somente pode existir se os clientes confidenciarem a ele o papel de intermediador financeiro.

Apesar das contribuições, esta pesquisa possui algumas ponderações. Na literatura, encontram-se estudos que buscam explicar a lealdade de clientes de bancos por meio da interação com outros constructos, como a percepção dos custos de mudança (Matos et al., 2009), o valor percebido (Brei \& Rossi, 2005) e a qualidade percebida (Prado, 2004). Esses constructos podem oferecer uma visão mais compreensiva das relações propostas neste estudo. De igual modo, não foram consideradas no modelo variáveis que potencialmente podem influenciar a percepção do correntista sobre o engajamento em responsabilidade ambiental do banco, como valores pessoais, consciência, conhecimento e comportamentos pró-ambientais.

Além disso, o delineamento da pesquisa não permite estabelecer quaisquer ilações de causalidade entre as variáveis. A amostra restringiu-se a uma indústria do ramo de serviços, e apenas correntistas de um banco foram entrevistados. Especificamente em relação ao fator intenções de negócios da lealdade atitudinal, não há como afirmar os motivos pelos quais um cliente apresenta baixas intenções comportamentais. Diante do questionamento, o entrevistado poderia, de fato, não querer o produto financeiro, desejar comprá-lo no Banco $X$ após o período determinado de seis meses ou querer comprá-lo na concorrência. Por fim, necessário faz-se replicar a escala desenvolvida para o constructo percepção de que um banco é ambientalmente responsável, principalmente em outros bancos no Brasil.

\section{Nota da Redação}

Este artigo foi apresentado no $6^{\circ}$ Congresso Latino-Americano de Varejo: Varejo e Desenvolvimento em Mercados Emergentes (CLAV) em 2013, organizado pelos professores Delane Botelho, Edgard Barki e Juracy Parente, promovido pelo Centro de Excelência em Varejo da FGV-EAESP (GVcev) 


\section{REFERÊNCIAS}

Bagozzi, R. P, \& Philips, L. W. (1982). Representing and testing organizational theories: a holistic construal. Administrative Science Quartely, 27(3), 459-489.

Baumann, C, Elliott, G, \& Hamin, H. (2011). Modeling customer loyalty in financial services: a hybrid of formative and reflective constructs. International Journal of Bank Marketing, 29(3), 247-267.

Bennett, R, \& Rundle-Thiele, S. (2002). A comparison of attitudinal loyalty measurement approaches. Journal of Brand Management, 9(3), 193-209.

Brei, V. A, \& Rossi, C. A. V. (2005). Confiança, valor percebido e lealdade em trocas relacionais de serviço: um estudo com usuários de internet banking no Brasil. RAC-Revista de Administração Contemporânea, 9(2), 145-168.

Chan, R. Y. K, \& Lau, L. B. Y. (2000). Antecedents of green purchases: a survey in China. The Journal of Consumer Marketing, 17(4), 338-357.

Chen, Y.-S. (2010). The drivers of green brand equity: green brand image, green satisfaction, and green trust. Journal of Business Ethics, 93(2), 307-319.

Chiou, J. S, \& Droge, C. (2006). Service quality, trust, specific asset investment, and expertise: direct and indirect effects in a satisfaction-loyalty framework. Journal of the Academy of Marketing Science, 34(4), $613-627$.

Churchill, G. A, Jr. (1979). A paradigm for developing better measures of marketing constructs. Journal of Marketing Research, 16(1), 64-73.

Cone, J. D, \& Hayes, S. C. (1977). Applied behavior analysis and the solution of environmental problems: human behavior and environment. In I. Altman, \& J. F. Wohlwill (Orgs.). Advances in theory and research (Vol. 2, pp. 129-179). New York: Plenum.

Corraliza, J. A, \& Berenguer, J. (2000). Environmental values, beliefs, and actions: a situational approach. Environment and Behavior, 32 (6), 832-848.

Coyne, K. P. (1986). Sustainable competitive advantage - what it is, what it isn't. Business Horizons, 29(1), 54-61.

Delgado-Ballester, E, \& Munuera-Aleman, J. L. (2001). Brand trust in the context of consumer loyalty. European Journal of Marketing, 35(11-12), 1238-1258.

Fornell, C., Johnson, M. D., Anderson, E. W., Cha, J., \& Bryant, B. E. (1996). The American customer satisfaction index: nature, purpose, and findings. The Journal of Marketing, 6o(4), 7-18.

Fraj, E, \& Martinez, E. (2006). Environmental values and lifestyles as determining factors of ecological consumer behaviour: an empirical analysis. Journal of Consumer Marketing, 23(3), 133-144.

Gordon, R, Carrigan, M, \& Hastings, G. (2011). A framework for sustainable marketing. Marketing Theory, 11(2), 143-163.

Grayson, K, \& Ambler, T. (1999). The dark side of long-term relationships in marketing services. Journal of Marketing Research, 36(1), 132-141.

Gremler, D. D, \& Brown, S. W. (1996). Service loyalty: its nature, importance and implications. In Edvardsson, B., Brown, S.W., Johnston, R., \& Scheuing, E. (Eds.). QUIS 5 advancing service quality: a global perspective (pp. 171-180). New York: ISQA.

Grove, S. J., Fisk, R. P., Pickett, G. M., \& Kangun, N. (1996). Going green in the service sector: social responsibility issues, implications and implementation. European Journal of Marketing, 30(5), 56-66.
Han, H., Hsu, L. T. J., Lee, J. S., \& Sheu, C. (2011). Are lodging customers ready to go green? An examination of attitudes, demographics, and eco-friendly intentions. International Journal of Hospitality Management, 30(2), 345-355.

Hair, J, Jr, Anderson, R. E, Tatham, R, \& Black, W. (2005). Análise multivariada de dados (5a ed.). São Paulo: Bookman.

Jones, T, \& Taylor, S. (2007). The conceptual domain of service loyalty: how many dimensions? Journal of Services Marketing, 21(1), 36-51.

Kantsperger, R, \& Kunz, W. H. (2010). Consumer trust in service companies: a multiple mediating analysis. Managing Service Quality, 20(1), 4-25.

Kline, R. B. (2011). Principles and practice of structural equation modeling (3rd ed.). New York: The Guilford Press.

Lewis, B. R, \& Soureli, M. (2006). The antecedents of consumer loyalty in retail banking. Journal of Consumer Behaviour, 5(1), 15-31.

Licata, J. W, \& Chakraborty, G. (2009). The effects of stake, satisfaction, and switching on true loyalty: a financial services study. International Journal of Bank Marketing, 27(4), 252-269.

Luo, X, \& Bhattacharya, C. B. (2006). Corporate social responsibility, customer satisfaction, and market value. Journal of Marketing, 70(4), 1-18.

Mandhachitara, R, \& Poolthong, Y. (2011). A model of customer loyalty and corporate social responsibility. The Journal of Services Marketing, 25(2), 122-133.

Matos, C. A. de, Henrique, J. L, \& Rosa, F. de. (2009). The different roles of switching costs on the satisfaction-loyalty relationship. International Journal of Bank Marketing, 27(7), 506-523.

Matute-Vallejo, J, Bravo, R, \& Pina, J. M. (2011). The influence of corporate social responsibility and price fairness on customer behaviour: evidence from the financial sector. Corporate Social Responsibility and Environmental Management, 18(6), 317-331.

McDonald, L. M, \& Rundle-Thiele, S. (2008). Corporate social responsibility and bank customer satisfaction: a research agenda. International Journal of Bank Marketing, 26(3), 170-182.

Moorman, C, Zaltman, G, \& Desphandé, R. (1992). Relationships between providers and users of marketing research: the dynamics of trust within and between organizations. Journal of Marketing Research, 29(3), 314-329.

Oliver, R. L. (2010). Satisfaction: a behavioral perspective on the consumer (2nd ed.). New York: ME Sharp.

Paiva, A. C. R. de. (2010). As atividades bancária e empresarial e 0 desenvolvimento sustentável. RAUSP-Revista de Administração da Universidade de São Paulo, 45(3), 297-304.

Pasquali, L. (Org.). (2010). Instrumentação psicológica: fundamentos e práticas. Porto Alegre: Artmed.

Prado, P. H. M. (2004). A avaliação do relacionamento sob a ótica do cliente: um estudo em bancos de varejo. Tese de doutorado, Administração de Empresas, Escola de Administração de Empresas de São Paulo da Fundação Getulio Vargas, São Paulo.

Romeiro, M. do C. (2006). Um estudo sobre o comportamento do consumidor ambientalmente favorável: uma verificação na região do $A B C$ Paulista. Tese de doutorado, Administração de Empresas, Departamento de Administração da Universidade de São Paulo, São Paulo.

Schwartz, S. H. (1992). Universals in the content and structure of values: theoretical advances and empirical tests in 20 countries. In Zanna, M. (Org.). Advances in Experimental Social Psychology (pp 1-65). Orlando: Academic. 
Schlegelmilch, B. B, Bohlen, G. M, \& Diamantopoulos, A. (1996). The link between green purchasing decisions and measures of environmental consciousness. European Journal of Marketing, 30(5), 35-55.

Sirdeshmukh, D, Singh, S, \& Sabol, B. (2002). Consumer trust, value and loyalty in relational exchanges. Journal of Marketing, 66(1), 15-37.

Sweeney, J, \& Swait, J. (2008). The effects of brand credibility on customer loyalty. Journal of Retailing and Consumer Services, 15(3), 179-193.

Tabachnick, B. G, \& Fidell, L. S. (2007). Using multivariate statistics ( $5^{\text {th }}$ ed.). Boston: Pearson.
Thompson, P. (1998). Bank lending and the environment: policies and opportunities. The International Journal of Bank Marketing, 16(6), $243-252$.

Uncles, M. D, Dowling, G. R, \& Hammond, K. (2003). Customer loyalty and customer loyalty programs. Journal of Consumer Marketing, 20(4), 294-316.

Weber, O. (2005). Sustainability benchmarking of European banks and financial service organizations. Corporate Social Responsibility and Environmental Management, 12(2), 73-87. 